\title{
Characterisation of the staphylococcal enterotoxin research method in a dairy product
}

\author{
L. Macaluso and C. Lapeyre \\ Agence Française de Sécurité Sanitaire des Aliments, 10 rue Pierre Curie, 94704 Maisons-Alfort Cedex, France
}

The staphylococcal enterotoxin research method is a quantitative method, involving a sample preparation and an immunoenzymatic detection. In order to estimate its performance characteristics, a method characterisation is carried out with a single dairy product and for staphylococcal enterotoxin A. Statistical analysis shows that the method is linear over a contamination interval between $0-1 \mathrm{ng}$ SEA per gram of cheese. The limit of detection is about $0.01 \mathrm{ng}$ SEA per gram of cheese and the limit of quantification is about $0.04 \mathrm{ng}$ SEA per gram of cheese. The intra laboratory repeatability and intermediate precision are estimated on two levels of contamination. The repeatability coefficient of variation is included between $3.1 \%$ and $6.2 \%$, the intermediate precision coefficient of variation is included between $4.7 \%$ and $11.0 \%$.

\section{Introduction}

Staphylococcal food poisoning is the second bacterial foodborne illness in France after Salmonella and before Clostridium perfringens [1-3]. Enterotoxins are proteins, whose molecular weight is between 26000 and 29000. Foods involved are usually rich in proteins, such as dairy products, meat products and egg mixtures. The staphylococcal enterotoxin A (SEA) is responsible for $75 \%$ of staphylococcal food poisonings. Nowadays, staphylococcal enterotoxin research is concentrated on dairy products, contaminated by $S$. aureus at a level more than $10^{4}$ cfu.g [4]. Products contaminated by staphylococcal enterotoxins are withdrawn from the market.

There is no reference method and no accreditation program on the staphylococcal enterotoxin topic. Due to the lack of a validated method, the AFSSA method is considered as the "reference method" by AFNOR (Association Française de Normalisation) and DGAL (Direction Générale de l'Alimentation) and by other laboratories.

The staphylococcal enterotoxin research method consists of two steps, sample preparation and immunoenzymatic detection. In order to characterize and to determine the method performance criteria, we have carried out a statistical intra laboratory evaluation.

A full method evaluation includes method characterisation and comparison with a reference method. Due to lack of reference method in staphylococcal enterotoxin research, we have only studied the method characterisation. Three criteria considered as compulsory (linearity, sensitivity and intra laboratory repeatability) have been estimated in addition to the intra laboratory intermediate precision, the limit of detection and the limit of quantification.

General guidelines of this method evaluation are described in the Guide d'évaluation et de validation d'une méthode d'analyse [5]. 


\section{Material and methods}

\section{Material}

Distilled water.

PBS (Phosphate Buffered Saline): sodium phosphate $10 \mathrm{mM}$ (Merck), sodium chloride 0.145 M (Merck), $\mathrm{pH}=7.4$.

PBS Tween: PBS with $0.1 \%$ Tween 20 .

Sodium hydroxide $5 \mathrm{~N}$ or $1 \mathrm{~N}$ (Merck).

Hydrochloric acid $5 \mathrm{~N}$ or $1 \mathrm{~N}$ (Merck).

Polyethylene glycol 20000 (Merck).

Dialysis tubings: Spectra/Por ${ }^{\circledR}$ molecular porous regenerated cellulose membranes, MWCO 6000-8000 (Poly-Labo).

Staphylococcal enterotoxin A (SEA) produced and purified at AFSSA Paris and used for artificial contamination of samples: solution at $96 \mathrm{ng}$ SEA per ml PBS with $2 \mathrm{mg}$ BSA (Bovine Serum Albumin) per $\mathrm{ml}$ and $0.02 \%$ sodium azide.

Experimental sample: soft cheese from supermarket.

\section{Methods}

\section{Sample preparation}

$12.5 \mathrm{~g}$ of cheese are mixed with $25 \mathrm{ml}$ of distilled water at $\theta \leq 40{ }^{\circ} \mathrm{C}$, using Ultra Turrax. The slurry is either artificially contaminated by SEA solution or not. The slurry is adjusted to $\mathrm{pH} \leq 4$ with $\mathrm{HCl}$ then centrifuged at $12500 \mathrm{~g}$, at $4{ }^{\circ} \mathrm{C}$ for $15 \mathrm{~min}$. The $\mathrm{pH}$ of the aqueous supernatant is adjusted to $7.3 \pm 0.3$ with $\mathrm{NaOH}$, centrifuged and filtered on glass wool. The filtered supernatant is concentrated by dialysis against PEG solution (15 g of PEG plus $50 \mathrm{ml}$ of distilled water), overnight, at $4{ }^{\circ} \mathrm{C}$.

The concentrated extract is recovered and adjusted to $2.5 \mathrm{ml}$ with PBS.

\section{Detection of SEA}

Detection of SEA in extracts is carried out by indirect double sandwich EIA (Enzyme ImmunoAssay) [6]. This detection method uses specific monoclonal antibodies as coating antibodies and polyspecific polyclonal antibodies as probing antibodies. The presence of enterotoxins is revealed by using goat anti-rabbit immunoglobulins coupled to horseradish peroxydase and determined by a colorimetric measure. In the same step, to quantify the SEA amount in samples, SEA solution at an increasing final concentration from $0.125 \mathrm{ng} \mathrm{ml}^{-1}$ to $1 \mathrm{ng} \mathrm{ml}^{-1}$ is incubated separately in order to obtain a SEA standard curve: $\mathrm{DO}=f\left[\mathrm{SEA}\left(\mathrm{ng} \cdot \mathrm{ml}^{-1}\right)\right]$.

Results are determined by measuring absorbance at $405 \mathrm{~nm}$ using a microtiter plate reader. The amount of SEA $\left(Y\right.$ ng. ml $\left.{ }^{-1}\right)$ in extracts is calculated from the SEA standard curve.
The absorbance reader is a MR 5000 model (Dynatech).

\section{Method characterisation}

\section{Linearity}

Experiments are carried out with 3 replicates $(n=3)$ of the 6 contamination levels $(k=6)-0,0.2,0.4,0.6,0.8$ and $1 \mathrm{ng}$ SEA per gram of cheese $(X)$. Samples are contaminated by SEA solution before the extraction procedure.

Our purpose is to characterize the linearity of the entire method, that is to say sample preparation and immunoenzymatic detection.

Experiments on pure solutions are not carried out because this would only characterize the detection method.

From the $18(N=\mathrm{k} n=18)$ data obtained, the following statistical parameters are calculated: the slope (b), the standard deviation of the slope ( $\mathrm{Sb}$ ), the intercept (a) and the standard deviation of the intercept $(\mathrm{Sa})$, and the correlation coefficient $(r)$.

To determine the linearity of the method, the following statistical tests are studied:

- Comparison of the intercept with zero by the Student test $(t$-test $)(\alpha$-error $=5 \% ; d f($ degrees of freedom $)=N-2)$

$$
t=\frac{|\mathrm{a}|}{\mathrm{Sa}}
$$

If $t<t(\alpha ; N-2)$, the intercept is not significantly different from zero.

- Homogeneity of intra group variances $\left(S_{j}^{2}\right)$ determination by the Cochran test $(C$-test $)(\alpha$-error $=5 \% ; k ; n)$

$$
C=\frac{S_{\max }^{2}}{\sum_{j=1}^{k} S_{j}^{2}}
$$

If $C<C(\alpha ; k ; n)$, intra group variances are homogeneous.

- Slope significance test by the Fisher test (F-test): Guidelines are given in table I.

If $F_{1}>F(\alpha ; 1 ; N-2)$, the linear regression slope is significative.

- Linear regression significance test by the Fisher test: Guidelines are given in table II.

If $F_{2}<F(\alpha ; k-2 ; N-k)$, the linear regression model is valid.

Intra laboratory repeatability and intermediate precision (study of recovery level's quality)

According to the Guide d'évaluation et de validation d'une méthode d'analyse [5], experiments must be carried out with 3 contamination levels. But, within the context of a preliminary study, our purpose is to estimate the intra laboratory 
Table I. Slope significance test.

\begin{tabular}{|c|c|c|c|c|}
\hline Variations & Degrees of freedom (df) & Sum of squares & Variances & F calculated \\
\hline Total variance & $N-1$ & $\sum T^{2}=\sum_{j=1}^{k} \sum_{i=1}^{n j}\left(Y_{i j}-\overline{\bar{Y}}\right)^{2}$ & & \\
\hline Regression variance & 1 & $\sum I^{2}=b^{2} \sum_{j=1}^{k} n_{j}\left(\bar{X}_{j}-\bar{X}\right)^{2}$ & $S_{l}^{2}=\sum I^{2}$ & $F_{1}=\frac{S_{l}^{2}}{S_{R}^{2}}$ \\
\hline Residual variance & $N-2$ & $\sum R^{2}=\sum T^{2}-\sum I^{2}$ & $S_{R}^{2}=\frac{\sum R^{2}}{N-2}$ & \\
\hline
\end{tabular}

Table II. Linear regression significance test.

\begin{tabular}{lcccc}
\hline Variations & $d f$ & Sum of squares & Variances & $F$ calculated \\
\hline Experimental variation & $N-k$ & $\sum E^{2}=\sum_{j=1}^{k} \sum_{i=1}^{n j}\left(Y_{i j}-\overline{Y_{j}}\right)^{2}$ & $S_{E}^{2}=\frac{\sum E^{2}}{N-k}$ \\
Regression variation & $k-2$ & $\sum L^{2}=\sum R^{2}-\sum E^{2}$ & $S_{L}^{2}=\frac{\sum L^{2}}{k-2} \quad F_{2}=\frac{S_{L}^{2}}{S_{E}^{2}}$ \\
\hline
\end{tabular}

repeatability and intermediate precision. Experiments are only carried out with 2 contamination levels.

To determine the quality criteria of the method, experiments are carried out with 6 replicates $(n=6)$ of 2 contamination levels ( 0.3 and $0.7 \mathrm{ng}$ SEA per gram of cheese) for 3 days $(k=3)$. Samples are contaminated by SEA solution before the extraction procedure.

For the intermediate precision study, the only variation parameter is the day of the sample preparation and SEA detection. The response is SEA recovery level. The repeatability $(r)$, the repeatability standard deviation $\left(S_{r}\right)$, the repeatability coefficient of variation $\left(C V_{r}\right)$, the intermediate precision $(R)$, the intermediate precision standard deviation $\left(S_{R}\right)$ and the intermediate precision coefficient of variation $\left(C V_{R}\right)$ are estimated from guidelines given by NF ISO 5725-

2 Norm (December 1994) [7].

To characterize the quality of the method, the following statistical tests are carried out:

- Homogeneity of intra group variances determination by the Cochran test $(\alpha$-error $=5 \%$ and $1 \% ; k ; n)$.

Guidelines are described in the paragraph "Linearity" (equation (2)).

- Determination of isolated and aberrant data by the Grubbs test.

Statistical data are estimated from averages $\overline{Y_{j}}$ of each contamination level. The $G$-test allows to determine isolated or aberrant values among averages.
Inferior datum

$$
G_{i}=\frac{\left(\overline{\bar{Y}}-\overline{Y_{j \min }}\right)}{S}
$$

Superior datum

$$
G_{S}=\frac{\left(\overline{Y_{j \max }}-\bar{Y}\right)}{S}
$$

With

$$
\begin{gathered}
\overline{\bar{Y}}=\frac{\sum_{j=1}^{k} \bar{Y}_{j}}{k} \\
S=\sqrt{\frac{1}{k-1} \sum_{j=1}^{k}\left(\bar{Y}_{j}-\bar{Y}\right)^{2}}
\end{gathered}
$$

If $G<G(\alpha$-error $=5 \%$; $k)$, there is no isolated value. If $G<G(\alpha$-error $=1 \% ; k)$, there is no aberrant value.

- Determination of repeatability and intermediate precision criteria: guidelines are given in table III.

Limits of detection and quantification (method of blank matrix)

Experiments are carried out with 20 uncontaminated cheese samples which are extracted. For each blank extract, the absorbance (OD) at $405 \mathrm{~nm}$ is measured. 
Table III. Determination of repeatability and intermediate precision parameters.

\section{Number of groups}

\section{$k$}

Number of replicates

per group

Total number of

experiments

$$
n
$$

$N$

$k n$

Sum of averages

$\sum_{j=1}^{k} \overline{Y_{j}}$

Squares of averages' sum $\sum_{j=1}^{k} \overline{Y_{j}^{2}}$

Sum of variances $\quad \sum_{j=1}^{k} S_{j}^{2}$

Repeatability variance

Inter group variance

Intermediate precision

variance

General average

Repeatability

Repeatability coefficient of variation

Intermediate precision Intermediate precision coefficient of variation$$
S_{g}{ }^{2} \frac{\left(k \sum_{j=1}^{k} \overline{Y_{j}^{2}}\right)-\left(\sum_{j=1}^{k} \overline{Y_{j}}\right)^{2}}{k(k-1)}-\frac{S_{r}^{2}}{n}
$$

$$
S_{R}{ }^{2} \quad S_{r}^{2}+S_{g}{ }^{2}
$$$$
\overline{\bar{Y}} \quad \frac{\sum_{j=1}^{k} \overline{Y_{j}}}{k}
$$

$r \quad 2.83 \mathrm{Sr}$

$\mathrm{CVr} \quad \frac{S_{r}}{\overline{\bar{Y}}}{ }^{*} 100$

R 2.83SR

CVR $\quad \frac{S_{R}}{\overline{\bar{Y}}} * 100$

$$
S_{r}^{2} \quad \frac{\sum_{j=1}^{k} S_{j}^{2}}{k}
$$

The average $\mathrm{OD}$, noted $\overline{\mathrm{OD}}$, and the standard deviation $\mathrm{S}_{\mathrm{OD}}$ are calculated from these 20 measures.

Limits of detection and quantification are estimated from these two data.

- Limit of detection (LOD)

$$
\mathrm{LOD}=\overline{\mathrm{OD}}+3 \mathrm{~S}_{\mathrm{OD}}
$$

- Limit of quantification (LOQ)

$$
\mathrm{LOQ}=\overline{\mathrm{OD}}+10 \mathrm{~S}_{\mathrm{OD}}
$$

Limits are estimated in the unity ng. $\mathrm{ml}^{-1}$ from a SEA standard curve.

Determination of statistical data

Statistical data are generated using Excel software.

\section{Results and discussion}

\section{Linearity}

Figure 1 gives a visual plot of the experimental data and regression line.

From these data, the linear regression parameters are calculated and the t-test is carried out. The results are shown in table IV.

The intercept is not significantly different from zero with $\alpha$-error $=5 \%$. The dairy extract does not interfere with SEA detection. The method sensitivity is determined from the linear regression slope.

- Homogeneity of intra group variances determination

Table $\mathrm{V}$ gives statistical results about homogeneity of variances.

Variances $S_{j}^{2}$ are homogeneous with $\alpha$-error $=5 \%$.

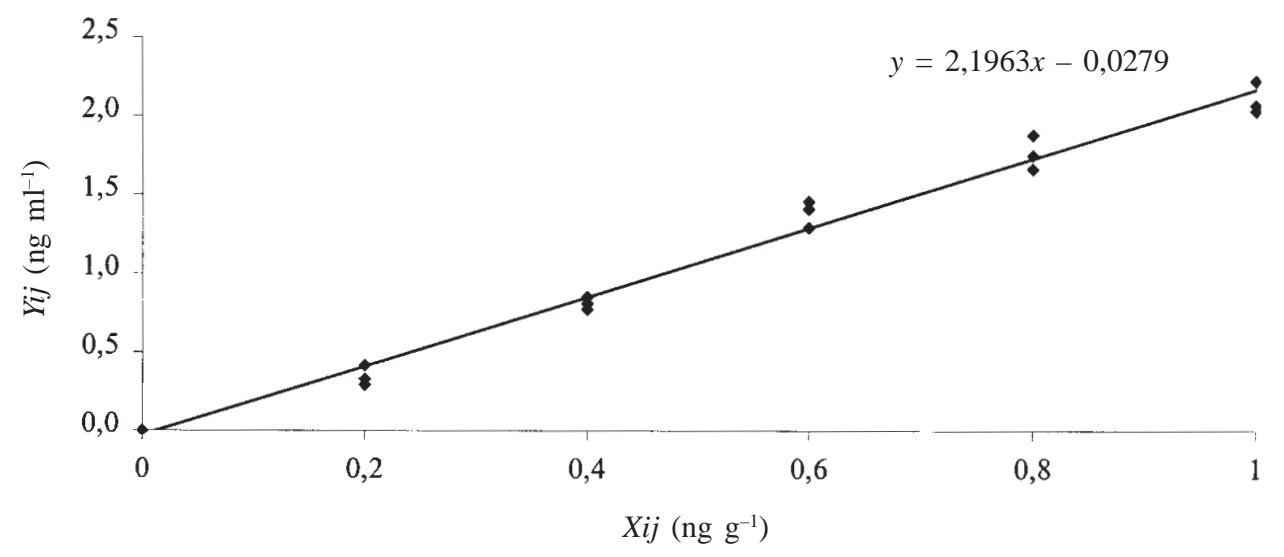

Figure 1. Experimental data and regression line. 
Table IV. Linear regression parameters and results of the t-test.

Estimate Theoretical Unity
$(\alpha=5 \%)$

\begin{tabular}{lccc} 
Sensitivity b & 2.1963 & & \\
Sb & 0.0861 & & \\
Intercept a & -0.0279 & & $\mathrm{ng} \cdot \mathrm{ml}^{-1}$ \\
$\mathrm{Sa}$ & 0.0154 & & $\mathrm{ng} \cdot \mathrm{ml}^{-1}$ \\
Correlation coefficient $r$ & 0.9935 & & \\
t-test & 1.8065 & $\mathrm{t}(5 \% ; 16)$ & \\
\multicolumn{1}{c}{$\mathrm{ns}$} & 2.12 & \\
& &
\end{tabular}

ns: non significant

Table V. Homogeneity of intra groups variances test.

$\begin{array}{ccc} & \text { Estimate } & \text { Theoretical }(\alpha=5 \%) \\ \text { C-test } & 0.3333 & \mathrm{C}(5 \% ; 6 ; 3) \\ & \mathrm{ns} & 0.616\end{array}$

ns: non significant
- Slope significance test

Statistical results are given in table VI and show a significant slope, which means a linear dependence between the added SEA contamination $(\mathrm{X})$ and the SEA detected amount (Y) with $\alpha$-error $=5 \%$.

- Linear regression significance test

Statistical results are given in table VII and show a significant linear regression, which means that the linear model is suitable with $\alpha$-error $=5 \%$.

\section{Intra laboratory repeatability and intermediate precision (study of recovery level's quality)}

- Homogeneity of intra groups variances determination Table VIII gives statistical results.

Variances $S^{2}$ are homogeneous with $\alpha$-error $=5 \%$ and $\alpha$-error $=1 \%$.

- Determination of isolated and aberrant values

Statistical results are shown in table IX and are calculated from averages $\overline{Y_{j}}$ of each contamination level.

For each contamination level, the G-test shows no isolated value and no aberrant value.

Table VI. Slope significance test.

\begin{tabular}{lccccc}
\hline Variations & $d f$ & Sum of squares & Variances & Estimated $F$ & Theoretical $F$ (5 \%; $;$ 16) \\
\hline Total variance & 17 & 10.2637 & & & 4.49 \\
Regression variance & 1 & 10.1300 & 10.1300 & 1211.5624 & $\mathrm{~s}$ \\
Residual variance & 16 & 0.1338 & 0.0084 & & \\
\hline
\end{tabular}

s: significant

Table VII. Linear regression significance test.

\begin{tabular}{lccccc}
\hline Variations & $d f$ & Sum of squares & Variances & Estimated $F$ & Theoretical $F(5 \%$; $;$ 12) \\
Experimental variation & 12 & 0.0703 & 0.0059 & $\mathrm{~ns}$ & 3.26 \\
Regression variation & 4 & 0.0635 & 0.0159 & 2.7092 &
\end{tabular}

ns: non significant

Table VIII. Homogeneity test of intra groups variances.

\begin{tabular}{|c|c|c|c|c|c|c|}
\hline & \multicolumn{3}{|c|}{ Level $1=0.3 \mathrm{ng} \mathrm{g}^{-1}$} & \multicolumn{3}{|c|}{ Level $2=0.7 \mathrm{ng} \mathrm{g}^{-1}$} \\
\hline & Group 1 & Group 2 & Group 3 & Group 1 & Group 2 & Group 3 \\
\hline$n$ & 6 & 6 & 6 & 6 & 6 & 6 \\
\hline$S_{j}^{2}$ & 16.3261 & 6.6627 & 5.3313 & 4.2113 & 1.6348 & 0.5535 \\
\hline$\overline{Y_{j}}(\%)$ & 44.84 & 50.09 & 54.22 & 45.87 & 48.97 & 45.92 \\
\hline C & & 0.5765 & & & 0.6581 & \\
\hline C $(5 \% ; 3 ; 6)$ & \multicolumn{6}{|c|}{0.707} \\
\hline$C(1 \% ; 3 ; 6)$ & \multicolumn{6}{|c|}{0.793} \\
\hline$C$-test & & ns & & \multicolumn{3}{|c|}{ ns } \\
\hline
\end{tabular}

ns : non significant 
Table IX. Isolated and aberrant data determination.

\begin{tabular}{lccl}
\hline Level & Inferior & Superior & \\
\hline $1\left(0,3 \mathrm{ng} \mathrm{g}^{-1}\right)$ & 1.0374 & 0.9578 & \\
$2\left(0,7 \mathrm{ng} \mathrm{g}^{-1}\right)$ & 0.5901 & 1.1546 & Estimated \\
Isolated values $(\alpha=5 \%)$ & 1.155 & 1.155 & Theoretical \\
Aberrant values $(\alpha=1 \%)$ & 1.155 & 1.155 & \\
G-test & $\mathrm{ns}$ & $\mathrm{ns}$ & \\
\hline
\end{tabular}

ns: non significant

- Intra laboratory repeatability and intermediate precision Repeatability and intermediate precision parameters are estimated by applying mathematical formulas given in table III.

Table $\mathrm{X}$ shows statistical results.

\section{Limit of detection and limit of quantification}

Table XI gives statistical results. Limits (ng. $\left.\mathrm{ml}^{-1}\right)$ are calculated from a SEA standard curve. The concentrations in the unity ng. ${ }^{-1}$ (ng SEA per gram of cheese) are determined from the extract volume $(2.5 \mathrm{ml})$, the sample mass $(12.5 \mathrm{~g})$ and corrected by the average recovery level, estimated by the quality study.

\section{Conclusion and prospects}

Results allow us to estimate the method performance characteristics.

The method characterisation is carried out with a single dairy matrix. The purpose of the next study is the evaluation of the method in several food matrixes.
Table XI. Limit of detection and limit of quantification (ng. $\mathrm{ml}^{-1}$ and $\mathrm{ng} \cdot \mathrm{g}^{-1}$ )

\begin{tabular}{ccccc}
\hline & & DO & {$[S E A] n g \cdot \mathrm{ml}^{-1}$} & {$[S E A] n g \cdot g^{-1}$} \\
\hline LOD & $m_{b}+3 S_{b}$ & 0.1831 & 0.03 & 0.01 \\
LOQ & $m_{b}+10 S_{b}$ & 0.2809 & 0.1 & 0.04 \\
\hline
\end{tabular}

In the same way, it would be interesting:

- to study method repeatability and intermediate precision through a larger scale of concentrations;

- to evaluate the research method for other staphylococcal enterotoxins.

\section{References}

1. Bergdoll, M.S. In Foodborne Bacterial Pathogens; Mickeal, P., Doyle Ed., New York: Marcel Dekker, Inc., 1989; pp 464-513.

2. De Buyser, M. L.; Lapeyre, C.; Dilasser, F.; Janin, F. Coll. Soc. Microbiol./Alim. 1997, 11, 7-16.

3. Haeghebaert, S.; Le Querrec, F.; Vaillant, V.; Delarocque Astagneau, E.; Bouvet, P. Bull. Epidémiol. Hebd. 1998, $\mathrm{N}^{\circ} 41$, pp 177-181.

4. Arrêté Ministériel du 30 mars 1994 relatif aux critères microbiologiques auxquels doivent satisfaire les laits de consommation et les produits à base de lait lors de leur mise sur le marché (Journal Officiel de la République Française, 21 avril 1994).

5. Bouvier, J. C. Guide d'évaluation et de validation d'une méthode d'analyse; report INRA Narbonne, 1994.

6. Lapeyre, C.; Janin, F.; Kaveri, S.V. Food Microbiol. 1988, 5, 25-31.

7. NF ISO 5725-2 Norm (December 1994). Application de la statistique. Exactitude (justesse et fidélité) des résultats et méthodes de mesure. Partie 2 : Méthode de base pour la détermination de la répétabilité et de la reproductibilité d'une méthode de mesure normalisée.

Table X. Intra laboratory repeatability and intermediate precision.

\begin{tabular}{lccccccc}
\hline Level & Recovery level SEA (\%) & $S_{r}(\%)$ & $r(\%)$ & $C V_{r}(\%)$ & $S_{R}(\%)$ & $R(\%)$ & $C V_{R}(\%)$ \\
\hline $0.3 \mathrm{ng} \mathrm{g}^{-1}$ & 49,71 & 3,1 & 8,7 & 6,2 & 5,5 & 15,5 & 11,0 \\
$0.7 \mathrm{ng} \mathrm{g}^{-1}$ & 46,92 & 1,5 & 4,1 & 3,1 & 2,2 & 6,3 & 4,7 \\
\hline
\end{tabular}

